\title{
Debridement for surgical wounds (Review)
}

\author{
Smith F, Dryburgh N, Donaldson J, Mitchell M
}

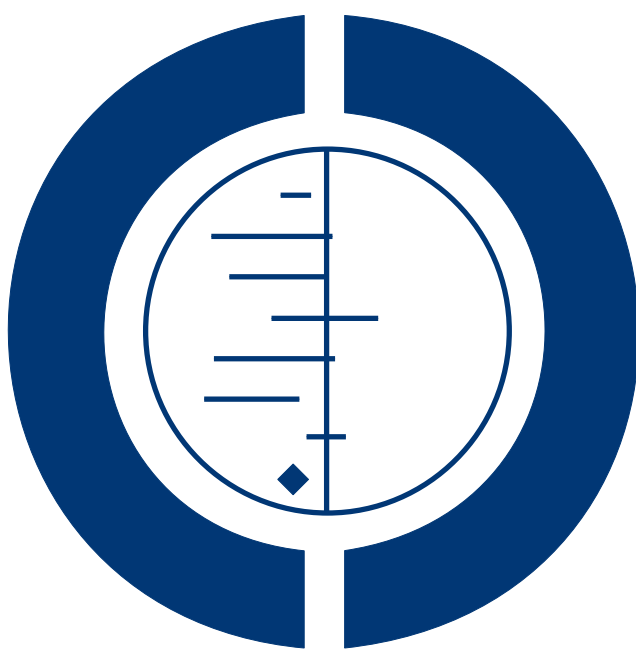

THE COCHRANE COLLABORATION $^{\circledR}$

This is a reprint of a Cochrane review, prepared and maintained by The Cochrane Collaboration and published in The Cochrane Library 2013, Issue 9

http://www.thecochranelibrary.com

\section{WILEY}


TABLE OF CONTENTS

HEADER . . . . . . . . . . . . . . . . . . . . . . . . . . . . . . . . . . . . 1

ABSTRACT . . . . . . . . . . . . . . . . . . . . . . . . . . . . . . . . . . . . . . . . . . . . . . .

PLAIN LANGUAGE SUMMARY . . . . . . . . . . . . . . . . . . . . . . . . . . . . . . . . . . 2

BACKGROUND . . . . . . . . . . . . . . . . . . . . . . . . . . . . . . . . . . . . . . . . . .

OBJECTIVES . . . . . . . . . . . . . . . . . . . . . . . . . . . . . . . . . . . . . . . $4 \begin{gathered}4 \\ \text { O }\end{gathered}$

METHODS . . . . . . . . . . . . . . . . . . . . . . . . . . . . . . . . . . . . . . . .

Figure 1. . . . . . . . . . . . . . . . . . . . . . . . . . . . . . . . . . . . . . 7

Figure 2. . . . . . . . . . . . . . . . . . . . . . . . . . . . . . . . . . . . . . 8

RESULTS . . . . . . . . . . . . . . . . . . . . . . . . . . . . . . . . . . . . . . . 8

DISCUSSION . . . . . . . . . . . . . . . . . . . . . . . . . . . . . . . . . . . . . 12

AUTHORS' CONCLUSIONS . . . . . . . . . . . . . . . . . . . . . . . . . . . . . . . . . . . .

ACKNOWLEDGEMENTS . . . . . . . . . . . . . . . . . . . . . . . . . . . . . . . . . . . 13

REFERENCES . . . . . . . . . . . . . . . . . . . . . . . . . . . . . . . . . . . . . . 14

CHARACTERISTICS OF STUDIES . . . . . . . . . . . . . . . . . . . . . . . . . . . . . . . . . . . . . .

DATA AND ANALYSES . . . . . . . . . . . . . . . . . . . . . . . . . . . . . . . . . . . 30

WHAT'S NEW . . . . . . . . . . . . . . . . . . . . . . . . . . . . . . . . . . . . 30

HISTORY . . . . . . . . . . . . . . . . . . . . . . . . . . . . . . . . . . . . . . 30

CONTRIBUTIONS OF AUTHORS . . . . . . . . . . . . . . . . . . . . . . . . . . . . . . . . . .

DECLARATIONS OF INTEREST . . . . . . . . . . . . . . . . . . . . . . . . . . . . . . . . . . . . . .

SOURCES OF SUPPORT . . . . . . . . . . . . . . . . . . . . . . . . . . . . . . . . . . . . . . . . . .

INDEX TERMS . . . . . . . . . . . . . . . . . . . . . . . . . . . . . . . . . . . . 32

Debridement for surgical wounds (Review)

Copyright $\odot 2013$ The Cochrane Collaboration. Published by John Wiley \& Sons, Ltd. 


\title{
[Intervention Review] \\ Debridement for surgical wounds
}

\author{
Fiona Smith ${ }^{1}$, Nancy Dryburgh ${ }^{2}$, Jayne Donaldson ${ }^{3}$, Melloney Mitchell $^{4}$ \\ ${ }^{1}$ School of Nursing, Midwifery and Social Care, Faculty of Health, Life \& Social Sciences, Edinburgh Napier University, Edinburgh, \\ UK. ${ }^{2}$ Edinburgh, UK. ${ }^{3}$ School of Nursing, Midwifery and Social Care, Edinburgh Napier University, Edinburgh, UK. ${ }^{4}$ The Royal \\ Infirmary, Edinburgh, UK \\ Contact address: Fiona Smith, School of Nursing, Midwifery and Social Care, Faculty of Health, Life \& Social Sciences, Edinburgh \\ Napier University, Sighthill Campus, Edinburgh, EH11 4BN, UK. f.smith@napier.ac.uk. \\ Editorial group: Cochrane Wounds Group. \\ Publication status and date: New search for studies and content updated (no change to conclusions), published in Issue 9, 2013. \\ Review content assessed as up-to-date: 13 June 2013.
}

Citation: Smith F, Dryburgh N, Donaldson J, Mitchell M. Debridement for surgical wounds. Cochrane Database of Systematic Reviews 2013, Issue 9. Art. No.: CD006214. DOI: 10.1002/14651858.CD006214.pub4.

Copyright (C) 2013 The Cochrane Collaboration. Published by John Wiley \& Sons, Ltd.

\begin{abstract}
A B S T R A C T
Background

Surgical wounds that become infected are often debrided because clinicians believe that removal of this necrotic or infected tissue will expedite wound healing. There are numerous methods available but no consensus on which one is most effective for surgical wounds.
\end{abstract}

\section{Objectives}

To determine the effect of different methods of debridement on the rate of debridement and healing of surgical wounds.

\section{Search methods}

In March 2013, for this third update, we searched the Cochrane Wounds Group Specialised Register; the Cochrane Central Register of Controlled Trials (CENTRAL) (The Cochrane Library); Ovid MEDLINE; Ovid MEDLINE (In-Process \& Other Non-Indexed Citations); Ovid EMBASE; and EBSCO CINAHL.

\section{Selection criteria}

We included randomised controlled trials (RCTs) with outcomes including at least one of the following: time to complete debridement or time to complete healing.

\section{Data collection and analysis}

Two review authors independently reviewed the abstracts and titles obtained from the search, extracted data independently using a standardised extraction sheet and independently assessed methodological quality. One review author was involved in all stages of the data collection and extraction process, thus ensuring continuity.

\section{Main results}

Five RCTs (159 participants) were eligible for inclusion; all compared treatments for infected surgical wounds and reported time required to achieve a clean wound bed (complete debridement). One trial compared an enzymatic agent (streptokinase/streptodornase) with saline-soaked dressings. Four trials compared the effectiveness of dextranomer beads or paste with other products (different comparator in each trial) to achieve complete debridement. Meta-analysis was not possible due to the unique comparisons within each trial. One trial reported that dextranomer achieved a clean wound bed significantly more quickly than Eusol, and one trial comparing enzymatic debridement with saline-soaked dressings reported that the enzyme-treated wounds were cleaned more quickly. However, methodological quality was poor in these two trials.

Debridement for surgical wounds (Review)

Copyright ( 2013 The Cochrane Collaboration. Published by John Wiley \& Sons, Ltd. 


\section{Authors' conclusions}

There is a lack of large, high-quality published RCTs evaluating debridement per se, or comparing different methods of debridement for surgical wounds, to guide clinical decision-making.

\section{PLAIN LANGUAGE SUMMARY}

\section{Debridement for surgical wounds}

Following surgery most surgical wounds heal naturally with no complications. However, complications such as infection and wound dehiscence (opening) can occur which may result in delayed healing or wound breakdown. Infected surgical wounds may contain dead (devitalised) tissue. Removal of this dead tissue (debridement) from surgical wounds is believed to enable wound healing. Many methods are available to clinicians to debride surgical wounds. This review showed that there is insufficient valid research evidence to recommend any one particular method.

There is a clear need for more research into which method is most effective in removing dead tissue from surgical wounds that have become infected.

\section{B A C K G R O U N D}

Surgical wounds, by definition, are initially acute and most heal naturally without delay or complications (Bale 1997; Baxter 2003). However, complications such as infection and wound dehiscence (opening) may occur, and may result in either delayed wound healing or wound breakdown, or both. Wounds with surgical site infections may contain devitalised (dead) tissue. The appearance, colour and texture of this tissue may vary from hard, black tissue (necrotic or eschar) to a soft fibrous yellow or green tissue (slough) (Thomas 1999; Vowden 1999a; Ramundo 2000; Stotts 2000; O'Brien 2003a). This may be accompanied by increased production of fluid (exudate) and the presence of an odour (Dealey 1994; O’Brien 2003a).

There is a widely held belief that wound healing is impeded by the presence of devitalised, necrotic tissue and wounds containing such material do not heal successfully (Baharestani 1999; Lewis 2000; Stotts 2000; NICE 2001; O’Brien 2002). Non-viable tissue not only inhibits the growth of epithelial tissue, but also increases the production of exudate, impairs assessment of the wound bed, and makes it more difficult to achieve wound closure, thus having an adverse effect on quality of life (Baharestani 1999). Although Baharestani 1999 details a number of reasons for the removal of the dead tissue (as detailed above), these reasons do not appear to be supported by robust, scientific evidence.

Debridement is the process whereby foreign material and dead or damaged tissue and debris are removed from a wound (Vowden 1999a; O’Brien 2002; O’Brien 2003c). Debridement of wounds includes any method that removes infected or contaminated tissue, cell debris or dead, devitalised, fibrous material (frequently classified as eschar or slough) to create a clean wound bed (Vowden 1999a; NICE 2001; O'Brien 2002). Debridement is thought to provide a foundation for the subsequent healing of wounds (O’Brien 2003b).

Debridement may be achieved by a variety of methods including: surgery; biosurgical (larvae) debridement; autolytic debridement; mechanical debridement; chemical debridement and enzymatic debridement.

\section{Surgical or sharp debridement}

Surgical debridement may be achieved by the aggressive excision of all devitalised tissue using surgical techniques (Thomas 1999; Vowden 1999b; Sibbald 2000; Schultz 2003). Disadvantages associated with this method are the requirement for hospital admission, the administration of an anaesthetic with associated complications, and time in the operating theatre. It is also associated with pain, bleeding and excision of healthy tissue and, as such, is not suitable or desirable for all patients (Baharestani 1999; Thomas 1999; Vowden 1999b; Sibbald 2000; Schultz 2003). On the other hand, sharp debridement involves the excision of small quantities of dead tissue by a clinician using scissors or a scalpel (O'Brien 2003a; O'Brien 2003c). This procedure may be performed in a community or hospital setting (Poston 1996). However, for both surgical and sharp procedures, issues of patient consent, training and skill of the clinician must be considered (Ashworth 2002). 


\section{Biosurgical/biological debridement}

In biosurgical or biological debridement, sterile larvae (maggots) of the Lucilia sericata species of greenbottle fly are applied to a sloughy wound. There, the larvae are capable of producing powerful proteolytic enzymes that destroy the dead tissue by liquefying and ingesting it. Healthy tissue in the wound bed is not damaged and, although there are aesthetic considerations, larvae are increasingly being used for wound debridement (Baharestani 1999; Lewis 2000; O’Brien 2003a).

\section{Autolytic debridement}

Over time, naturally occurring enzymes will eventually break down and dissolve dead or sloughy tissue in wounds. This natural process is promoted by the maintenance of a moist environment through judicious use of dressings and topical agents (e.g. hydrogels, semiocclusive and occlusive wound dressings). Many of these dressings hydrate and remove black, necrotic tissue and slough (Baharestani 1999; Vowden 1999a; Lewis 2000). Dextranomer is an example of a hydroscopic dressing which has a high absorptive capacity and is capable of removing bacteria, debris and absorbing wound exudate, thereby facilitating autolytic debridement. However worldwide production of dextranomer beads and paste was discontinued in 2007, with the exception of the paste which is still available in South Africa.

\section{Mechanical debridement}

Mechanical methods of debridement are non-selective and may result in damage to healthy tissue (Baharestani 1999). These methods include: wet to dry debridement, wound cleansing debridement and whirlpool debridement (Vowden 1999a; Ramundo 2000; O’Brien 2003a; Stotts 2004; Falabella 2006).

\section{Wet to dry debridement}

The wet to dry method of debridement involves the application of a saline-soaked gauze dressing to a wound. The moist dressing induces separation of the devitalised tissue and, once dry, the dressing is removed, together with the slough and necrotic tissue. This process is continued until all the devitalised tissue is removed. This is reported to be a painful procedure and may damage healthy tissue; fibres may be left in the wound and the dressing does not provide a barrier to bacterial contamination (Baharestani 1999; Ramundo 2000; O’Brien 2003a; Stotts 2004).

\section{Wound cleansing debridement}

Wound cleansing debridement involves irrigating a wound with a continuous or intermittent flow of fluid delivered under high pressure. The force of the fluid is between 8 and 12 pounds per square inch (psi), and is sufficient to remove devitalised tissue and wound bacteria (Baharestani 1999; Ramundo 2000). Newer wound cleansing systems use pressurised saline delivered via a nozzle at between 12,800 and 15,000 psi (Granick 2006).

\section{Whirlpool debridement}

Whirlpool debridement is used for large wounds on the trunk or extremities. The affected person is immersed in a whirlpool bath, where the vigorous action of the water and its hydrating effect loosen the surface bacteria and devitalised tissue, and allow them to be washed away (Baharestani 1999; Ramundo 2000).

\section{Chemical debridement}

A range of chemical agents, including hypochlorites such as EUSOL (Edinburgh University Solution of Lime) and Dakin's Solution (sodium hypochlorite), hydrogen peroxide and iodine, have been used to promote debridement of wounds. The use of chemical agents remains a controversial area, in which any benefits need to be judged against any detrimental effects on the process of healing (Brennan 1985; Baharestani 1999; Hofman 2002; Ayello 2004).

\section{Enzymatic debridement}

Topical enzymatic preparations are applied to moist (or moistened) devitalised tissue. Such preparations include: streptokinase/streptodornase (Lewis 2000; O’Brien 2003a), collagenase (Ramundo 2000; Stotts 2004), papain/urea, and a combination of fibrinolysin and deoxyribonuclease (Ramundo 2000; Stotts 2004). This method has a number of disadvantages, including a requirement for frequent dressing changes and a slow rate of debridement. Worldwide production of the enzymatic preparation of streptokinase/streptodornase has now been discontinued.

\section{Overview}

There is considerable debate about the appropriateness and efficacy of debridement methods (Ashworth 2002). A systematic review published in 1999 indicated that there were no studies comparing non debridement with debridement and therefore the benefits of debridement on wound healing were unclear (Bradley 1999). A guidance document on the use of debriding agents for difficultto-heal surgical wounds highlighted the lack of sufficient evidence (and the corresponding absence of randomised controlled trials (RCTs)) to support any particular method of debridement (NICE 2001). However a Cochrane Review on the debridement of diabetic foot ulcers found evidence suggesting that the rate of healing increased when a hydrogel dressing was used in comparison to a gauze dressing (Edwards 2010). The choice of debriding agent and method is usually made on the basis of the clinician's expertise 
and knowledge, the available resources and cost (Flanagan 1999). Since wound management choices, however, continue to increase, as do the cost of products, the choice of debridement method or agent should be guided by good evidence (Lewis 2000). An up-todate review of debridement for surgical wounds is therefore necessary, to enable evidence-based clinical decision-making.

\section{O B JECT IVES}

To determine the effects of different debriding methods on the rate of debridement and healing of surgical wounds.

\section{METHODS}

\section{Criteria for considering studies for this review}

\section{Types of studies}

We included all RCTs evaluating debridement in the management of surgical wounds.

\section{Types of participants}

We included studies on people of any age, in any care setting, with a surgical wound that required debridement, but excluded studies of wounds that were not caused by surgery (i.e. trauma wounds, burns, abscesses or sinuses, pressure ulcers, leg ulcers, diabetic foot ulcers, fungating tumours and wounds caused by the removal of foreign bodies).

\section{Types of interventions}

We considered any method of debridement compared with a control regimen (a placebo, an alternative method of debridement, any other therapy or no treatment) including:

- surgical, such as the excision of all devitalised tissue, or sharp, such as the excision of small quantities of non-viable tissue using a scalpel or scissors;

- biosurgical, such as the use of sterile larvae;

- autolytic, such as the use of hydrogels/hydrocolloids to promote a moist environment;

- mechanical, such as wet to dry debridement, high-pressure irrigation or whirlpool debridement;

- chemical, such as the use of Eusol or Dakin's Solution; and

- enzymatic debridement, such as topical enzymatic preparations (e.g. collagenase).

\section{Types of outcome measures}

A trial report had to provide at least one of the primary outcomes to be included in the review.

\section{Primary outcomes}

- Time to complete debridement.

- The proportion of wounds completely debrided during the trial period.

- The rate of reduction in wound size expressed in either absolute or relative terms.

- The proportion of wounds completely healed during the trial period.

- Time to complete healing.

\section{Secondary outcomes}

When reported, we recorded the following secondary outcomes:

- patient satisfaction (e.g. pain associated with treatment as recorded using a recognised pain scale);

- rate of infection;

- quality of life;

- length of hospital stay;

- cost-effectiveness (e.g. as presented in a cost-effectiveness analysis, which may include: nursing time; time taken to change dressing; number of dressing changes required; cost of dressing materials);

- serious adverse events (life-threatening or those leading to hospitalisation);

- other adverse events (those leading to discontinuation of treatment).

\section{Search methods for identification of studies}

The search methods used in the second review update can be found in Appendix 1.

\section{Electronic searches}

In March 2013, for this third update, we searched the following databases for reports of eligible trials:

- the Cochrane Wounds Group Specialised Register (searched 28 March 2013);

- the Cochrane Central Register of Controlled Trials (CENTRAL) (The Cochrane Library 2013, Issue 2);

- Ovid MEDLINE (2011 to March Week 2 2013);

- Ovid MEDLINE (In-Process \& Other Non-Indexed Citations, March 26, 2013);

- Ovid EMBASE (2011 to 2013 Week 12); and

- EBSCO CINAHL (2011 to 22 March 2013).

We used the following strategy in the Cochrane Central Register of Controlled Trials (CENTRAL): 
\#1 MeSH descriptor Debridement explode all trees

\#2 debrid*

\#3 MeSH descriptor Larva explode all trees

\#4 (larva* or maggot* or biosurgery or bio-surgery)

\#5 wound* NEXT irrigat*

\#6 wound* NEXT cleans*

\#7 whirlpool

\#8 collagenase* or fibrinolytic* or proteolytic* or trypsin or streptokinase or streptodornase or varidase

\#9 hypochlorite or hydrogen NEXT peroxide

\#10 malic NEXT acid or benzoid NEXT acid or salicylic NEXT acid or propylene NEXT glycol

\#11 dakin solution

\#12 dextranomer* or cadexomer or xerogel or eusol or debrisan \#13 polysaccharide NEXT bead* or polysaccharide NEXT paste* \#14 iodoflex or iodosorb

\#15 intrasite NEXT gel or intrasitgel or sterigel or granugel or nugel or purilon NEXT gel or purilon or vigilon

\#16 gauze NEXT dressing* or adherent NEXT dressing* or absorbent NEXT dressing* or tulle NEXT dressing* or polysaccharide NEXT dressing* or hydrofibre NEXT dressing* or "wet to dry dressing" or "wet to dry dressings"

\#17 hydrocolloid* or granuflex or tegasorb or aquacel or hydrocoll or combiderm or duoderm

\#18 alginate NEXT dressing* or foam NEXT dressing* or hydrogel* $^{*}$ or saline NEXT gauze

\#19 MeSH descriptor Honey explode all trees

\#20 honey*

\#21 \#1 OR \#2 OR \#3 OR \#4 OR \#5 OR \#6 OR \#7 OR \#8 OR \#9 OR \#10 OR \#11 OR \#12 OR \#13 OR \#14 OR \#15 OR \#16 OR \#17 OR \#18 OR \#19 OR \#20)

\#22 MeSH descriptor Surgical Wound Infection explode all trees \#23 MeSH descriptor Surgical Wound Dehiscence explode all trees

\#24 surg* NEAR/5 infection*

\#25 surg* NEAR/5 wound*

\#26 (postoperative or post-operative) NEAR/5 infection*

\#27 exudat* NEAR/5 wound*

\#28 exudat* NEAR/5 cavit*

\#29 necrot* $^{*}$ NEAR/5 wound

\#30 necrot* NEAR/5 cavit*

\#31 (\#22 OR \#23 OR \#24 OR \#25 OR \#26 OR \#27 OR \#28

OR \#29 OR \#30)

\#32 (\#21 AND \#31)

The search strategies for Ovid MEDLINE, Ovid EMBASE and EBSCO CINAHL can be found in Appendix 2; Appendix 3 and Appendix 4 respectively. We combined the MEDLINE search with the Cochrane Highly Sensitive Search Strategy for identifying randomised trials in MEDLINE: sensitivity- and precision-maximising version (2008 revision); Ovid format (Lefebvre 2011). We combined the EMBASE and CINAHL searches with the trial filters developed by the Scottish Intercollegiate Guidelines Network
(SIGN 2007). There were no restrictions with respect to language, date of publication or study setting.

\section{Searching other resources}

We contacted manufacturers of wound products by e-mail for details of published, unpublished and ongoing trials (Smith \& Nephew Healthcare Ltd; Convatec Ltd; Johnston \& Johnston; Medihoney). To date we have identified no new citations for this review through these contacts. We checked the citations within obtained studies to identify additional papers.

\section{Data collection and analysis}

\section{Selection of studies}

Two review authors (ND and FS) independently assessed for relevance and design the titles and abstracts of studies identified. They obtained full versions of articles that met the inclusion criteria of this initial assessment. A third review author (MM) was consulted for adjudication on some abstracts. All rejected titles and abstracts were reviewed by $(\mathrm{MM})$.

\section{Data extraction and management}

We used a standardised extraction sheet to record and summarise details of the studies. Two review authors (ND and JD) independently performed data extraction. Discrepancies were resolved by discussion and referred to a third review author (FS).

We extracted the following data:

- general information: author(s), title, source, contact address, year of study, country of study, language of publication, year of publication;

- trial characteristics: design (RCT), randomisation method, manner of recruitment, sampling method, duration of intervention period, length of follow up, reason for and number of dropouts and withdrawals, adverse events;

- participants: baseline characteristics such as sex, age, type of wound, wound size, duration of wound, method of debridement, prevalence of co-morbidities (e.g. diabetes), study inclusion and exclusion criteria, all by treatment group;

- intervention: detailed description of the comparison dressing/method, co-interventions, duration;

- outcome measures;

- primary outcomes: time to complete debridement, proportion of wounds completely debrided, reduction in wound size, proportion of wound completely healed, time to complete healing;

- secondary outcomes: patient satisfaction (pain assessment), rate of infection, quality of life, length of hospital stay, costeffectiveness, serious/other adverse events; 
- any co-interventions; and

- where trials were sponsored by the dressing manufacturer.

\section{Assessment of risk of bias in included studies}

For the update of this review we assessed each included study for risk of bias, without blinding to journal or authorship, using the Cochrane Collaboration tool (Higgins 2011). This tool addresses six specific domains, namely sequence generation, allocation concealment, blinding, incomplete outcome data, selective outcome reporting and other issues (e.g. extreme baseline imbalance) (see
Appendix 5 for details of the criteria on which the judgements were based). We assessed blinding and completeness of outcome data for each outcome separately. We completed a 'Risk of bias' table for each eligible study.

We presented an assessment of risk of bias using a 'Risk of bias' summary figure (Figure 1 and Figure 2), which presents all of the judgements in a cross-tabulation of study by entry. This display of the internal validity indicates the weight the reader may give the results of each study. We classed studies as being at high risk of bias overall if any one of the criteria were judged to be at high risk of bias. 
Figure I. Risk of bias summary: review authors' judgements about each risk of bias item for each included study.

\begin{tabular}{|c|c|c|c|c|c|c|}
\hline & 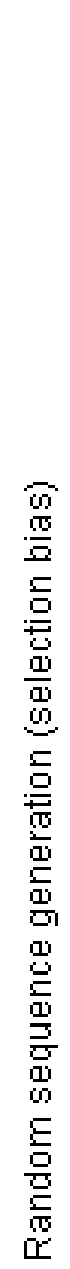 & 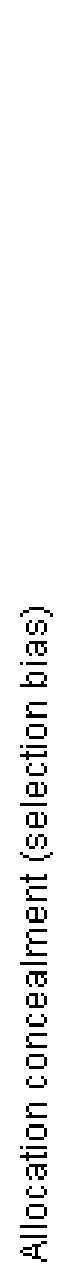 & 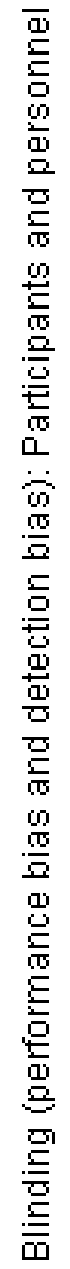 & 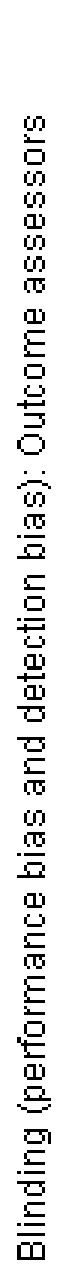 & 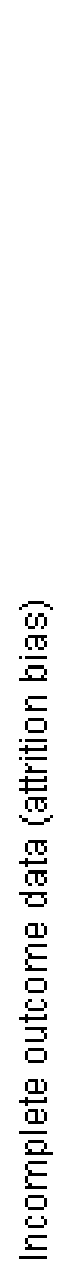 & 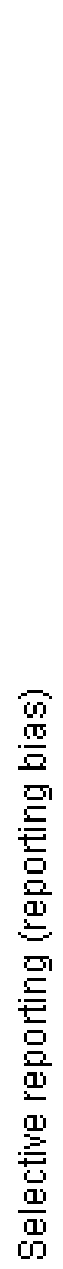 \\
\hline Goode 1979 & $?$ & $?$ & $?$ & + & + & + \\
\hline Michiels 1990 & + & $?$ & $?$ & $?$ & $?$ & + \\
\hline Poulson 1983 & $?$ & + & $?$ & $?$ & & $?$ \\
\hline Sondergaard 1982 & + & + & $?$ & $?$ & & $?$ \\
\hline Young 1982 & $?$ & $?$ & $?$ & $?$ & + & + \\
\hline
\end{tabular}


Figure 2. Risk of bias graph: review authors' judgements about each risk of bias item presented as percentages across all included studies.

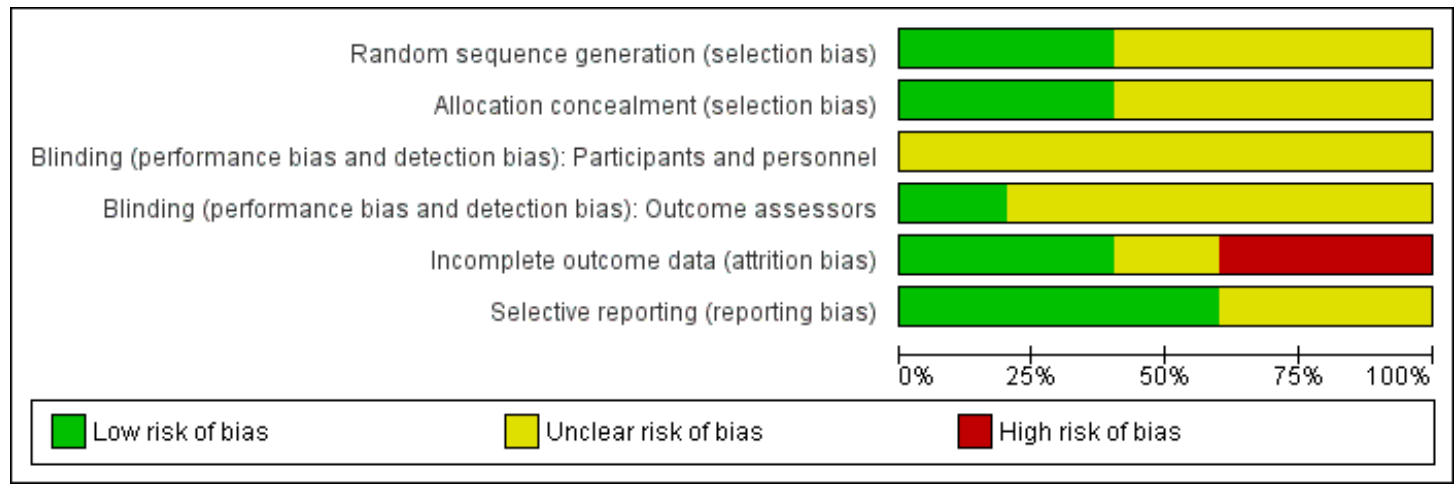

\section{Assessment of heterogeneity}

Should data be available in future updates, we will explore both clinical and statistical heterogeneity. In the absence of clinical and statistical heterogeneity we will apply a fixed-effect model to pool data, if appropriate. In the presence of statistical heterogeneity (as estimated by the $\mathrm{I}^{2}$ statistic where values of $\mathrm{I}^{2}$ over $75 \%$ indicate a high level of heterogeneity) (Higgins 2003) we will apply a random-effects model for meta-analysis. Where synthesis is inappropriate we will undertake a narrative overview. If there are any costeffectiveness data then these will be summarised narratively.

\section{Data synthesis}

Where appropriate data were entered into RevMan 5 by one review author (ND) and checked by two others (JD) and (FS). We converted continuous data (e.g. total area healed, or changes in volume of ulcers) to the standardised mean difference (or a weighted mean difference, when plausible) and calculated overall effect size (with 95\% CI). We analysed time to wound healing and time to return to work as survival (time to event) data, using the appropriate analytical method (as per the Cochrane Handbook for Systematic Reviews of Interventions version 5.0 (Higgins 2011)).

\section{Subgroup analysis and investigation of heterogeneity}

Should data be available in future updates, we may use subgroup analysis to investigate the effect of pre-existing pathology (e.g. diabetes), or ages of subjects (e.g. below or above age 14 years), or location of wound (e.g. abdominal, thoracic wounds) on surgical wound debridement.

\section{RE S U L T S}

\section{Description of studies}

None of the titles or abstracts ( 425 citations) retrieved in the updated search were relevant to this review.

Our original 2008 search identified 2087 titles and abstracts. A total of 30 abstracts were potentially relevant and we obtained the full publications of these. Five of these publications were in languages other than English and after translation it was apparent that only one of these was a RCT. Two authors (ND and MM) independently read the publications and applied the inclusion and exclusion criteria. They made referral to a third author (JD) regarding three trials. Six RCTs were initially identified as having met the inclusion criteria (see 'Characteristics of included studies' table); the randomisation status of one was unclear and the author did not respond to requests for further information (Zeitani 2004) therefore we excluded this trial (see 'Characteristics of excluded studies' table), leaving five included trials (Goode 1979; Sondergaard 1982; Young 1982; Poulson 1983; Michiels 1990). All identified trials were published between 1979 and 1990; trial sizes ranged from 18 to 50 participants and, where reported, ages ranged from three years to 91 years. Small sample size was the main deficiency of the five trials and none of the trials reported an a priori sample size calculation. 
All the trials compared treatments for infected post surgical wounds and, although the term debridement was mentioned in only one of the five trials(Michiels 1990), each trial reported the time required to obtain a clean wound bed. As the debridement of wounds includes any method that removes infected or contaminated tissue, cell debris or devitalised material to create a clean bed, we considered the five trials eligible for inclusion in the review. The five trials entered people with post surgical wounds all described as infected, or at risk of infection, and reported that the wounds were either left open, or required opening and drainage for infection. Reporting of the type and site of the surgery and extent of the wound was variable. Poulson 1983 provided the most detailed breakdown of the type of surgery performed and inclusion criteria indicating the minimum length and depth of the wounds. Sondergaard 1982 reported inclusion of wounds involving the subcutaneous tissue and Young 1982 included wounds left open from the muscle layer outwards. Exclusion criteria was not reported in the trials by Goode 1979and Young 1982.

Four of the trials evaluated the effectiveness of dextranomer beads or paste in providing a clean wound bed. One compared the effectiveness of dextranomer with Eusol-soaked dressings (Goode 1979). Michiels 1990 compared dextranomer paste with $10 \%$ aqueous polyvinylpyrrolidone. Dextranomer beads were compared with $0.1 \%$ chloramine soaked packs in the trial by Sondergaard 1982 and with a polymer foam dressing in another trial (Young 1982). One trial compared the enzyme preparation of streptokinase/streptodornase with saline-soaked dressings (Poulson 1983). Time to a clean wound bed was reported in all trials and was the primary outcome prior to wound closure or discharge from hospital (Goode 1979; Poulson 1983; Michiels 1990). Time to complete healing was reported in two trials (Sondergaard 1982; Young 1982).

Small sample size was the major deficiency of the five trials. The sample sizes ranged from 18 to 50 .

\section{Risk of bias in included studies}

We classified studies as being at high risk of bias overall if any of the following four criteria were judged to be at high risk of bias: randomisation sequence generation, allocation concealment, blinding and incomplete outcome data addressed.

All five included trials (Goode 1979; Sondergaard 1982; Young 1982; Poulson 1983; Michiels 1990) were classified as 'unclear' for the majority of the four key criteria (see 'Risk of bias' tables for each study).

\section{Allocation}

\section{Adequacy of the randomisation process}

All studies reported that allocation was randomised but the method of generating the randomisation sequence was not always clear. We judged sequence generation to be adequate in two studies: Michiels 1990 reported the use of a randomisation list and Sondergaard 1982 randomised patients in blocks of four. Hence, we judged these two studies to be at low risk of bias for this domain. We judged the remaining three studies as at unclear risk of bias as they did not report sufficient information to make a judgement with respect to the method of sequence generation: Goode 1979 and Young 1982 used a randomised card system, whilst Poulson 1983 arranged for the hospital pharmacy to control the randomisation but none of them stated how the sequence was generated.

\section{Adequacy of allocation concealment}

Two studies reported adequate allocation concealment and were judged to be at low risk of bias for this domain. Poulson 1983 reported that the hospital pharmacy prepared and provided the ampoules of the treatment and control solutions (treatment and control solutions were both $20 \mathrm{ml}$ vials of clear fluid). Sondergaard 1982 reported the use of numbered sealed envelops which, although not described as opaque, we have judged it to be adequate allocation concealment. The extent of the allocation concealment in the remaining trials was unclear either because insufficient information was provided or studies did not state that allocation was concealed.

\section{Blinding}

\section{Blinding of outcome assessors}

Studies were regarded as at lower risk of bias if the outcome assessor was blinded to the intervention. Only one trial (Goode 1979) reported that the outcome assessor was blinded to treatment and the assessment was carried out using photographs rather than a visual inspection. The remaining trials did not report if the outcome assessors were blinded and were judged as at unclear risk of bias for this domain (Sondergaard 1982; Young 1982; Poulson 1983; Michiels 1990).

\section{Blinding of participants and personnel}

None of the included studies reported blinding of participants or personnel involved in the care of the participants. It would be difficult to blind the personnel involved in applying the wound dressings where the control and treatment dressings had very different properties; the same would apply to the participants. It is reasonable to argue that blinding of these two would not adversely influence the outcomes measured within the trials, however the judgement remains as at unclear risk of bias. 


\section{Incomplete outcome data}

Goode 1979 and Young 1982 do not record any withdrawals or dropouts and the number of participants included at the start of each trial is reflected in the results and therefore were judged to be at low risk of bias for this domain. Two studies were classified to be at high risk of bias for this domain: Poulson 1983 reported three withdrawals which were excluded from the final analysis and Sondergaard 1982 reported six withdrawals and in the tables of results indicated that these participants were excluded. It is not clear if these were also excluded from the final analysis. Also, the dropout rate in Sondergaard 1982 was $21 \%$ (we originally prespecified greater than $80 \%$ ) and hence was judged to be unacceptable. The remaining trial reported limited information and was judged to be 'unclear' for risk of bias in this domain (Michiels 1990).

\section{Selective reporting}

No study protocols were available. However, we judged Goode 1979, Michiels 1990 and Young 1982 to be at low risk of bias for this domain because they adequately reported the expected study outcomes. We judged Sondergaard 1982 and Poulson 1983 'unclear' due to poor reporting.

\section{Effects of interventions}

\section{Comparison I: Dextranomer beads compared with Eusol gauze (one RCT, 20 participants)}

Goode 1979 compared dextranomer beads (an autolytic debridement agent) with Eusol-soaked ribbon gauze in 20 patients with infected surgical wounds, following appendectomy or bowel surgery.

\section{Primary outcomes}

- Outcome 1 - Time to a clean wound bed and secondary wound closure:

Resolution of erythema and oedema, absence of pus or slough and the formation of granulation tissue, were used as the criteria to determine a clean wound bed. Mean time to a clean wound bed was significantly shorter with dextranomer; 8.1 days compared with 11.6 days for Eusol ( $\mathrm{P}<0.05$, Mann-Whitney U-test).

- Outcome 2 - Time to complete healing:

The time to complete healing was not reported, although the trialists report that one wound in each group healed without secondary closure.

\section{Secondary outcomes}

- Outcome 1 - Patient satisfaction: not reported.

- Outcome 2 - Rate of infection: not reported.

- Outcome 3 - Quality of life: not reported.

- Outcome 4 - Length of hospital stay:

Patients in the dextranomer group were described as having a shorter stay by a median of 2.2 days than the Eusol group, however no data for the control group were reported.

- Outcome 5 - Cost-effectiveness: not reported:

Goode 1979 commented on the higher cost of dextranomer $(£ 3.40$ per twice-daily dressing) but that the shorter hospital stay in the treatment group compensated for this. This claim was not supported by any data.

While Goode 1979 demonstrated methodological adequacy in allocation concealment and blinding of outcome assessment, an unclear randomisation process, a small sample size and insufficient data mean it is difficult to place much weight on these results. Furthermore the comparator (Eusol) is rarely used due to fears of harmful effects on healthy tissue (Morgan 1991; Morgan 2004).

\section{Comparison 2: Dextranomer paste compared with I $0 \%$ aqueous polyvinylpyrrolidone (one RCT, 40 participants)}

Michiels 1990 compared dextranomer paste with gauze dressings soaked in 10\% aqueous polyvinylpyrrolidone (an iodinebased chemical debridement agent) in people with infected surgical wounds following osteosynthesis, microsurgery and reconstructive procedures.

\section{Primary outcomes}

- Outcome 1 - Time to clean wound bed:

The disappearance or resolution of erythema, pus and debris, oedema, necrotic tissue and the presence of granulation tissue were used as the criteria to determine a clean wound bed. The results for each variable were assessed subjectively and presented individually. The development, validity and reliability of the assessment systems used was not reported, but the trialists did acknowledge that the evaluation was an approximation. The trial reported no significant difference between the treatment and control groups for the resolution of erythema, oedema, necrotic tissue and the development of granulation tissue. The handling and reporting of the data for the pus and debris criteria were unclear and subjective and the groups were not comparable at baseline with respect to the amount of pus and debris. Michiels 1990 reports that dextranomer significantly reduced the time taken to clean the wound bed compared with polyvinylpyrrolidone. A P value of less than 0.05 was reported (Student's $t$-test), however no data were provided, the outcome was subjective and the outcome assessment was not reported as masked to treatment. 
- Outcome 2 - Time to complete healing:

The duration of the trial was 12 days and treatment was discontinued when the wound was clean and had new granulation tissue. Time to complete healing was not reported.

\section{Secondary outcomes}

No secondary outcomes were reported in this trial.

The methodological quality of this trial was poor with only the completeness of follow up adequate. The validity of the results is questionable.

\section{Comparison 3: Streptokinase/streptodornase compared with saline-soaked dressing (one RCT, 2 I participants)}

One small randomised trial compared enzymatic debridement with streptokinase/streptodornase with saline-soaked dressings in people with infected abdominal surgical wounds following a range of operations (Poulson 1983).

\section{Primary outcomes}

- Outcome 1 - Time to clean wound bed:

The trial reported the number of days required for a clean wound bed and secondary suture. Statistical analysis of the data demonstrated that time to a clean wound bed or secondary suture was significantly shorter for the streptokinase/streptodornase group (mean 5 days (SD 2.16)) compared with the saline-soaked dressings group (mean 13.45 days (SD 6.77), $\mathrm{P}<0.05$ by both Student's $t$-test and Mann-Whitney U-test). Time to clean wound bed was analysed using the Student's $t$-test and Mann Whitney U-test. Time to debridement or discharge of the patient are time to event outcomes and so the treatment effect should have been expressed as a hazard ratio.

- Outcome 2 - Time to complete healing not reported.

\section{Secondary outcomes}

- Outcome 1 - Patient satisfaction: not reported.

- Outcome 2 - Rate of infection: not reported.

- Outcome 3 - Quality of life:

The trial reported that no patients in either group complained of significant discomfort from the wound.

- Outcome 4 - Length of hospital stay:

Patients in the streptokinase/streptodornase group were described as having a had a shorter stay by 8.5 days than the saline-soaked dressings group, however no data or statistics were included in the trial report.

- Outcome 5 - Cost-effectiveness: not reported.
Methodological adequacy is reported in the randomisation process, allocation concealment, blinded outcome assessment and completeness of follow up. However, poor handling and analysis of the data and a small sample size are deficiencies in this trial. The validity of the results is therefore questionable.

\section{Comparison 4: Dextranomer beads compared with 0.1\% chloramine-soaked dressings (one RCT, 28 participants)}

Sondergaard 1982 randomised 28 patients with infected open surgical wounds to the dextranomer or $0.1 \%$ chloramine group.

\section{Primary outcomes}

- Outcome 1 - Time to clean wound bed:

The number of days until the wounds were clinically clean were reported as a median of six days with dextranomer and five days with chloramine-soaked dressings (described as no significant difference, however no data provided). The criteria used to determine when the wound was clinically clean were not reported.

- Outcome 2 - Time from the start of the treatment until the patient was assessed as ready for outpatient treatment:

This was reported as a median of nine days for dextranomer and seven days for chloramine; the difference between the two groups was reported as not significant, however no variance data were reported.

- Outcome 3 - Time to complete healing:

The time to complete healing was reported as a median of 27 days for the dextranomer group and 20 days for the chloramine group (no variance data provided). This was described by the trialists as no significant difference between the groups.

\section{Secondary outcomes}

- Outcome 1 - Patient satisfaction:

The trialists reported that the dextranomer dressing was less painful as it was easier to remove. However, no data were included.

- Outcome 2 - Rate of infection: not reported.

- Outcome 3 - Quality of life: not reported.

- Outcome 4 - Length of hospital stay: not reported.

- Outcome 5 - Cost-effectiveness:

The average cost per change of dressing for the dextranomer group was 123 Danish Kroner compared with approximately 1.50 Danish Kroner for the chloramine group, however no further cost analysis was reported.

Methodological quality was poor and none of the adequacy criteria were met by this trial. 


\section{Comparison 5: Dextranomer beads compared with elastomer foam (one RCT, 50 participants)}

Young 1982 randomised 50 people with open, infected surgical wounds between treatment with dextranomer beads and a foam elastomer dressing.

\section{Primary outcomes}

- Outcome 1 - Time to clean wound bed: not reported.

- Outcome 2 - Time to complete healing:

There was no statistically significant difference in mean time to healing ( 40.92 days $(\mathrm{SD}=3.98)$ with dextranomer compared with 36.90 days $(\mathrm{SD}=3.18)$ for elastomer foam). Time to clean wound bed was analysed as continuous data, using the Student's $t$-test ( $\mathrm{P}$ $>0.05$ ). Time to a clean wound bed is a time to event outcome and so the treatment effect should have been expressed as a hazard ratio.

\section{Secondary outcomes}

- Outcome 1 - Patient satisfaction:

The trialists reported that comfort of the dressing was assessed by questioning the patient. Pain of the wound was graded and the mean time to a pain-free wound was reduced with dextranomer at 5.32 days $(S D=0.55)$ compared with 5.64 days $(S D=0.45)$ for foam. Once again the analysis of the data of time to a painfree wound should have been expressed as a hazard ratio.

- Outcome 2 - Rate of infection: not reported.

- Outcome 3 - Quality of life: not reported.

- Outcome 4 - Length of hospital stay: not reported.

- Outcome 5 - Cost-effectiveness:

Young 1982 discussed the cost of the dressings reporting that dextranomer was markedly less cost-effective than elastomer foam. However, no cost analysis data was included and only approximate costings from another dextranomer trial by Goode 1979 were quoted.

The trial is poorly conducted and fails to meet the methodological quality criteria. Poor handling and analysis of the data and a small sample size are deficiencies in this trial. The validity of the results presented is therefore questionable.

It was not possible to undertake any subgroup analyses.

\section{DISCUSSION}

Despite the availability of a range of debridement methods (see Background) and an increasing number of modern dressings, we identified only five poor-quality randomised controlled trials (RCTs), all conducted prior to 1990 . Two methods of debridement were employed in the included studies: autolytic debridement using dextranomer and enzymatic debridement using streptokinase/ streptodornase. It is important to note that no trials were identified by the search that compared debridement with no debridement of surgical wounds. This reflects earlier findings by Bradley 1999 and apart from the findings of Edwards 2010, who showed that the rate of healing of diabetic foot ulcers increased with a hydrogel dressing when compared with gauze, this review of the evidence would indicate that there is still little evidence to support the belief that debridement promotes wound healing. Also the merit of using gauze as a comparator could be questioned, as Pollard 2008 would argue that most, if not all modern dressings would demonstrate improvement in healing when compared with gauze. However, in contrast Ubbink 2006 found that time to complete wound healing was similar when comparing occlusive with gauze-based dressings for surgical wounds. It is beyond the scope of this review to postulate reasons for the lack of trials comparing debridement with no debridement: perceived ethical considerations may be a barrier to the conducting of such RCTs.

Although only five RCTs conducted prior to 1990 met the inclusion criteria for this review, a range of more recent research papers were identified but following closer scrutiny were all excluded (see 'Characteristics of excluded studies' table). It is apparent from these excluded studies that a range of debridement methods are being used in clinical practice, including surgical debridement (Zeitani 2004) and mechanical debridement (Allie 2004; Granick 2006), however these studies are not RCTs and therefore are highly susceptible to selection bias. It is disappointing that recently published studies are not employing more rigorous research methods that aim to minimise bias and therefore increase the confidence with which we can view the findings. The cost of conducting a RCT may be one consideration. Manufacturers of existing and new wound debridement products appear to use controlled trials, retrospective analysis of patient case notes and case studies as evidence of effectiveness.

The common outcome for the five included trials was time to a clean wound bed for infected post surgical wounds. Three out of the four trials comparing dextranomer with other products reported shorter time to a clean wound bed for dextranomer. The trial comparing streptokinase/streptodornase with saline dressings reported a shorter time to a clean wound bed with streptokinase/ streptodornase.

However, a number of trial deficiencies reduce the confidence by which we can draw any conclusions to inform practice. These deficiencies include:

1. poor quality of the trials;

2. small sample sizes;

3. limited range of treatments;

4. different control groups for each trial; 

5. lack of replication studies; and
6. inappropriate statistical analysis (time to event data not being analysed as such).

The methodological quality of the trials was variable, with small sample sizes, method of randomisation not always being clear, and inadequate allocation concealment. Data and statistical information were incomplete in three of the five trials. Blinding of the independent assessors would have been possible, but this was only clearly demonstrated in two studies (Goode 1979; Poulson 1983).

A limited range of treatments was identified with dextranomer beads or paste and different comparisons used in each trial, therefore it was not possible to pool the results. The rationale for choosing dextranomer for the treatment groups was not clear, apart from in Young 1982, who identified this as a new dressing, the trial being supported financially by the manufacturer. Dextranomer was significantly better than Eusol-soaked dressings (Goode 1979) but this result must be viewed with caution, as there were insufficient statistical data included in the small trial and methodological flaws in the trial. As worldwide production of dextranomer products has been discontinued, except for dextranomer paste (which is currently only available in South Africa), the impact on clinical practice of these findings is extremely limited.

The enzymatic agent streptokinase/streptodornase demonstrated a statistically significant reduction in the time to a clean wound bed when compared with saline-soaked dressings. Poor handling and analysis of the data was a limitation of this trial and it should be noted that this enzyme is no longer available worldwide.

There is a complete absence of adequately powered, methodologically robust RCTs evaluating contemporary debridement interventions for surgical wounds. The trials included in this review investigate treatments that are no longer available and the trials were of poor quality. Trials reflecting the wider range of surgical, biosurgical, mechanical, chemical and autolytic debridement methods, and agents for surgical wounds were not identified.

\section{AUTHORS'CONCLUSIONS}

\section{Implications for practice}

Existing RCTs of methods of debridement for surgical wounds are small, evaluate outdated products and are of poor methodological quality. Currently there is no RCT evidence to support any particular debridement method or agent for surgical wounds.

\section{Implications for research}

Current innovations in wound debridement strategies increase the options available to the practitioner. Adequately powered, methodologically robust RCTs evaluating contemporary debridement interventions for surgical wounds are needed to guide clinical decision-making. Future trials should compare current debridement methods, for example surgical debridement compared to high-powered saline jet (at high pressure up to 15,000 pounds per square inch) or honey compared with low-cost established alternatives such as hydrogel dressings. These studies should: report time to healing as well as time to a clean wound bed; use valid measures of wound healing; assess quality of life; cost-effectiveness and be reported in accordance with CONSORT requirements.

\section{ACKNOWLEDGEMENTS}

We would like to thank the Cochrane Wounds Group for their continual support and guidance throughout, specifically Sally BellSyer for her comments on the protocol and review and Ali BabaAkbari Sari and Ruth Foxlee for their assistance with the search strategy. We would like to thank the peer referees for their comments on the protocol and review and also the Editors (Nicky Cullum, David Margolis and Dirk Ubbink), the referees (Roy Buffery, Lois Orton, Jude Edwards and Alan Holloway), the statistician editor (Gill Worthy) and the copy editors (Elizabeth Royle, Margaret Carver and Jenny Bellorini). We would like to thank Oleg Borisenko and Jannie Hedegaard for their assistance with the translation of studies in Russian and Danish.

We would also like to acknowledge the support provided by the following people:

Heather Maxwell, Cochrane Peripheral Vascular Diseases Group, for her advice with the preparation of the review; Robert Rush, Statistician, Centre for Integrated Healthcare Research, Edinburgh, for statistical advice; Sheena Moffat, Information Services Advisor, Edinburgh Napier University, for her assistance with the search strategy; and Kay Penny, Lecturer, Edinburgh Napier University, for her assistance with the statistics.

This review has been part-funded by a research grant from the Centre for Integrated Health Care Research, Edinburgh. 


\section{R E F E R E N C E S}

\section{References to studies included in this review}

Goode 1979 \{published data only\}

Goode AW, Glazer G, Ellis BW. The cost effectiveness of dextranomer and Eusol in the treatment of infected surgical wounds. British Journal of Clinical Practice 1979;33(11-12): 325-6.

Michiels 1990 \{published data only\}

Michiels I, Christiaens M-R. Dextranomer (Debrisan) paste in post-operative wounds: a controlled study. Clinical Trials Journal 1990;27(4):283-90.

Poulson 1983 \{published data only\}

Poulson J, Kristensen VN, Brygger HE, Delikaris P. Treatment of infected surgical wounds with Varidase. Acta Chirurgica Scandinavica 1983;149(3):245-8.

Sondergaard 1982 \{published data only\}

Sondergaard JO, Galatius H. Debrisan compared with chloramine packs in the treatment of postoperative infected wounds [Debrisan versus kloramin-mecheved postoperative inficerede cikatricer]. Ugeskrift for Laeger 1982;144(21): $1523-5$.

Young 1982 \{published data only\}

Young HL, Wheeler MH. Report of the prospective trial of dextranomer beads (Debrisan) and silicone foam elastomer (silastic dressings in surgical wounds). British Journal of Surgery 1982;69(1):33-4.

\section{References to studies excluded from this review}

Allie 2004 \{published data only\}

Allie DE, Herbert CJ, Lirtzman MD, Wyatt CH, Keller VA, Souther SM, et al.Novel treatment strategy for leg and sternal wound complications after coronary graft surgery: bioengineered Apligraf. Annals of Thoracic Surgery 2004;78 (2):673-8.

Bethell 2003 \{published data only\}

Bethell E. Why gauze dressings should not be the first choice to manage acute surgical cavity wounds. Journal of Wound Care 2003;12(6):237-9.

Cannavo 1998 \{published data only\}

Cannavo M, Fairbrother G, Owen D, Ingle J, Lumley T. A comparison of dressings in the management of surgical abdominal wounds. Journal of Wound Care 1998;7(2): $57-62$.

Capasso 2003 \{published data only\} Capasso VA, Munro BH. The cost and efficacy of two wound treatments. AORN Journal 2003;77(5):984-1004.

Cohn 2004 \{published data only\}

Cohn SM, Lopez PP, Brown M, Namias N, Jackowskl J, Li $\mathrm{P}$, et al.Open surgical wounds: how does Aquacel compare with wet-to-dry gauze. Journal of Wound Care 2004;13(1): $10-2$.

De Feo 2001 \{published data only\}

De Feo M, De Sante LS, Ramano G, Renzulli A, Corter $\mathrm{AD}$, Utili R, et al.Treatment of recurrent staphylococcal mediastinitis: still a controversial issue. Annals of Thoracic Surgery 2001;75(2):538-42.

De Feo 2003 \{published data only\}

De Feo M, Gregorio R, Corter AD, Marra C, Amarelli C, Renzulli A, et al.Deep sternal wound infection: the role of early debridement surgery. European Journal of Cardiothoracic Surgery 2003;19(6):811-6.

Doughty 2005 \{published data only\} Doughty DB. Preventing and managing surgical wound dehiscence. Advances in Skin and Wound Care 2005;18(6): 319-22.

Douville 2004 \{published data only\} Douville EC, Asaph JW, Dworkin RJ, Handy JR, Canepa CS, Grunkemeier GL, et al.Sternal preservation: a better way to treat most sternal wound complications after cardiac surgery. Annals of Thoracic Surgery 2004;78(5):1659-64.

Edwards 1967 \{published data only\}

Edwards RH, Killen DA. Comparison of two methods of management of clean surgical wounds. JAMA 1967;201(1): $137-8$.

Foster 2000 \{published data only\}

Foster L, Moore P, Clark S. Comparison of hydrofibre and alginate dressings on open acute surgical wounds. Journal of Wound Care 2000;9(9):442-5.

Gliantsev 1996 \{published data only\} Gliantsev SO, Savvina TV. Comparative evaluation of activity of proteolytic enzymes used in surgery. Biulleten Eksperimentalnoi Biologii 1996;121(6):16-20.

Gottrup 2005 \{published data only\} Gottrup F. The significance of dressings and topical agents in secondary healing [Betydningen af bandage og lokale midler ved sekundaert helede kirurgiske sar]. Ugeskrift for Laeger 2005;167(47):4473-6.

Granick 2006 \{published data only\}

Granick MS, Posnett J, Jacoby M, Noruthun S, Ganchi PA, Datiashvili RO. Efficacy and cost-effectiveness of a highpowered parallel waterjet for wound debridement. Wound Repair and Regeneration 2006;14(4):394-7.

Guest 2005 \{published data only\}

Guest JF, Ruiz FJ. Modelling the cost implications of using carboxymethylcellulose dressing compared with gauze in the management of surgical wound healing by secondary intention in the US and UK. Current Medical Research and Opinion 2005;21(2):94-101.

Kuleshov 1992 \{published data only\}

Kuleshov SE, Kaem RI. The use of carbon dioxide laser in acute surgical infection of the soft tissues. Khirurgiia Moskva 1992;2:94-101.

Moore 2000 \{published data only\} Moore PJ, Foster L. Cost benefits of two dressings in the management of surgical wounds. British Journal of Nursing 2000;9(17):1128-32. 
Moore 2001 \{published data only\}

Moore OA, Smith LA, Campbell F, Seers K, McQuay

HJ, Moore RA. Systematic review of the use of honey as a wound dressing. BMC Complementary and Alternative Medicine 2001;1(2):2.

Moues 2004 \{published data only\} Moues CM, Vos MC, van Den Bemd GJCM, Stijnen T, Hovius SER. Bacterial load in relation to vacuum-assisted closure wound therapy: a prospective randomised trial. Wound Repair and Regeneration 2004;12(1):11-7.

Mulder 1995 \{published data only\}

Mulder GD. Evaluation of three nonwoven sponges in the debridement of chronic wounds. Ostomy/Wound

Management 1995;41(3):62-7.

Rand 1998 \{published data only\}

Rand RP, Cochran RP, Aziz S, Hofer BO, Allen MD, Verrier $\mathrm{ED}$, et al.Prospective trial of catheter irrigation and muscle flaps for sternal wound infection. Annals of Thoracic Surgery 1998;65(4):1046-9.

Soul 1978 \{published data only\}

Soul JA. A trial of Debrisan in the cleansing of infected surgical wounds. British Journal of Clinical Practice 1978;32 (6):172-3

Tolstykh 1987 \{published data only\}

Tolstykh PI, Glostishchev VK, Khanin AG, Aboyants RK, Yusuf MY, Antsyshkin VA. The effect of biologically active dressings of wounds upon the development of the wound process. Vestnivk Khirurgh IM I I Grekova 1987;138(3): 57-60.

Williams 1995 \{published data only\}

Williams P, Howells REJ, Miller E, Foster ME. A comparison of two alginate dressings used in surgical wounds. Journal of Wound Care 1995;4(4):170-2.

Zeitani 2004 \{published data only\}

Zeitani J, Bertoldo F, Bassano C, Penta de Peppo A, Pellegrino AP, El Fakhri FM, et al.Superficial wound dehiscence after median sternotomy: surgical treatment versus secondary wound healing. Annals of Thoracic Surgery 2004;77(2):672-5.

\section{Additional references}

\section{Ashworth 2002}

Ashworth J. Conservative sharp debridement: the professional and legal issues. Professional Nurse 2002;17 (10):585-8.

\section{Ayello 2004}

Ayello EA, Cuddigan JE. Debridement: controlling the necrotic/cellular burden. Advances in Skin and Wound Care 2004;17(2):66-78.

\section{Baharestani 1999}

Baharestani M. The clinical relevance of debridement. In: Baharestani M, Gottrup F, Holstein P, Vanscheidt W editor (s). The clinical relevance of debridement. Berlin: SpringerVerlag, 1999:1-15.
Bale 1997

Bale S, Jones V. Wound care nursing: a patient centred approach. London: Bailliere Tindall, 1997.

Baxter 2003

Baxter H. Management of surgical wounds. Nursing Times 2003;99(13):66-8.

Bradley 1999

Bradley M, Cullum N, Sheldon T. The debridement of chronic wounds: a systematic review. Health Technology Assessment 1999;3(17 Pt 1):iii-iv, 1-78.

Brennan 1985

Brennan SS, Leaper DJ. The effect of antiseptics on the healing wound: a study using the rabbit ear chamber. British Journal of Surgery 1985;72(October):780-2.

\section{Dealey 1994}

Dealey C. The care of wounds. The care of wounds. Oxford: Blackwell Scientific Publications, 1994.

\section{Edwards 2010}

Edwards J. Debridement of diabetic foot ulcers. Cochrane Database of Systematic Reviews 2010, Issue 1. [DOI: 10.1002/14651858.CD003556.pub2]

\section{Falabella 2006}

Falabella, AF. Debridement and wound bed preparation. Dermatologic Therapy 2006;19(6):317-25.

\section{Flanagan 1999}

Flanagan M. Reviewing the case for debridement. Journal of Wound Care 1999;8(6):267.

Higgins 2003

Higgins JPT, Thompson SG, Deeks JJ, Altman DG. Measuring inconsistency in meta-analyses. BMJ 2003;327 (7414):557-60.

\section{Higgins 2011}

Higgins JPT, Altman DG, on behalf of the Cochrane Statistical Methods Group and the Cochrane Bias Methods Group (Editors). Chapter 8: Assessing risk of bias in included studies. In: Higgins JPT, Green S (editors). Cochrane Handbook for Systematic Reviews of Interventions Version 5.1.0 [updated March 2011]. The Cochrane Collaboration, 2011. Available from www.cochrane-handbook.org.

Hofman 2002

Hofman D. Debridement-a nursing issue?. www.etrs.org/ bulletin9`3/section5.html 2002 (accessed 17 November 2005).

Lefebvre 2011

Lefebvre C, Manheimer E, Glanville J, on behalf of the Cochrane Information Retrieval Methods Group. Chapter 6: Searching for studies. In: Higgins JPT, Green $S$ (editors). Cochrane Handbook for Systematic Reviews of Interventions Version 5.1.0 [updated March 2011]. The Cochrane Collaboration, 2011. Available from www.cochrane-handbook.org.

\section{Lewis 2000}

Lewis R, Whiting P, ter Reit G, O'Meara S, Glanville J. $A$ rapid systematic review of the clinical effectiveness and cost 
effectiveness of debriding agents in treating surgical wounds healing by secondary intention. York: NHS Centre for Reviews and Dissemination, 2000.

\section{Morgan 1991}

Morgan DA. Chlorinated solutions - an update. Journal of Tissue Viability 1991;2:31-3.

\section{Morgan 2004}

Morgan DA. Formulary of wound management products: a guide for health care staff. 9th Edition. Haslemere, Surrey, UK: Euromed Communications Ltd, 2004:32-3.

\section{NICE 2001}

National Institute for Clinical Excellence. Guidance on the use of debriding agents and specialist wound care clinics for difficult to heal surgical wounds. http://www.nice.org.uk/ guidance/index.jsp?action=article\&o=32175 $($ accessed 8 July 2005).

\section{O'Brien 2002}

O'Brien M. Exploring methods of wound debridement. British Journal of Community Nursing 2002;7(12):10,12,14, 16-8.

\section{O'Brien 2003a}

O'Brien M. Exploring methods of wound debridement. In: White RJ editor(s). Trends in wound care. Vol. II. Dinton, Salisbury: Quay Books Division, MA Healthcare, 2003: 95-107.

\section{O'Brien 2003b}

O'Brien M. Debridement: ethical, legal and practical considerations. British Journal of Community Nursing 2003; 8(Suppl 3):23-5.

\section{O'Brien 2003c}

O'Brien M. Methods of debridement and patient focused care. Journal of Community Nursing 2003;17(11):17-25.

\section{Pollard 2008}

Pollard T. Now is the time to find a new benchmark. Journal of Wound Care 2008;17(3):93.

\section{Poston 1996}

Poston J. Surgical nurse: sharp debridement of devitalised tissue: the nurse's role. British Journal of Nursing 1996;5 (11):655-6, 658-62.

\section{Ramundo 2000}

Ramundo J, Wells J. Wound debridement. In: Bryant RA editor(s). Acute and chronic wounds: nursing management. 2nd Edition. St Louis: Mosby, 2000:157-78.

\section{Schultz 2003}

Schultz GS, Sibbald RG, Falanga V, Ayello EA, Dowsett C, Harding K, et al.Wound bed preparation: a systematic approach to wound management. Wound Repair and Regeneration 2003;11(Suppl 1):S1-28.

\section{Sibbald 2000}

Sibbald RG, Williamson D, Orsted HL, Campbell K, Keast D, Krasner D, et al.Preparing the wound bed - debridement, bacterial balance and moisture balance. Ostomy/Wound Management 2000;46(11):14-35.

\section{SIGN 2007}

Scottish Intercollegiate Guidelines Network. Search filters. www.sign.ac.uk/methodology/filters.html\#random (accessed 13 June 2013).

\section{Stotts 2000}

Stotts NA. Wound infection: diagnosis and management. In: Bryant RA editor(s). Acute and chronic wounds: nursing management. 2nd Edition. St Louis: Mosby, 2000:179-88.

\section{Stotts 2004}

Stotts NA. Wound infection: diagnosis and management. In: Morison MJ, Ovington LG, Wilkie K editor(s). Chronic wound care: a problem based approach. Edinburgh: Mosby, 2004:101-16.

\section{Thomas 1999}

Thomas AML, Moore K. The structure and composition of chronic wound eschar. Journal of Wound Care 1999;8(6): 285-90.

\section{Ubbink 2006}

Ubbink D, Vermeulen H, Goossens A, Kelner R, Lubbers M. Randomized clinical trial comparing modern versus gauze dressings to treat open wounds in surgical patients. 16th Conference of the European Wound Management Association; 2006, 18-20 May; Prague, Czech Republic. 2006.

\section{Vowden 1999a}

Vowden K, Vowden P. Wound debridement, part 1: nonsharp techniques. Journal of Wound Care 1999;8(5):237-40.

\section{Vowden 1999b}

Vowden K, Vowden P. Wound debridement, part 2: sharp techniques. Journal of Wound Care 1999;8(6):291-6.

* Indicates the major publication for the study 


\section{CHARACTERISTICS OF STUDIES}

\section{Characteristics of included studies [ordered by study ID]}

\section{Goode 1979}

Methods

Setting: hospital and outpatients, UK
RCT
Interventions

\begin{tabular}{l} 
Participants \\
(A) 10 \\
(B) 10 \\
13 men/7 women \\
Age: 24 to 91 years \\
Post surgical wounds, infected wounds left open for delayed closure, or closed wounds \\
requiring opening and drainage following infection \\
Inclusion criteria: patients at risk from wound infection, following abdominal surgery \\
for appendicitis or bowel surgery; wounds heavily contaminated at surgery and left open \\
for delayed primary closure; wounds closed at surgery but developed an abscess and \\
required removal of sutures and wound drainage \\
Exclusion criteria: none listed \\
\hline
\end{tabular}

All patients were given antibiotic cover prior to surgery for 48 to 72 hours postoperatively Each wound was photographed at the start, during and at the end of the trial

(A) Twice daily dressings of dextranomer granules covered with a light pack

(B) Twice daily dressings of Eusol and paraffin-soaked ribbon gauze

All other wound procedures were identical for both groups

Independent assessor decided when the wound was clean and could be closed by secondary suture

Outcomes

Primary outcomes:

(1) Mean time to wound closure (SD not reported):

(A) 8.1 days

(B) 11.6 days

Statistical difference $\mathrm{P}<0.05$ (Mann-Whitney U-test)

(2) Time to complete healing not reported

Secondary outcomes:

(1) Patient satisfaction: not reported

(2) Rate of infection: not reported

(3) Quality of life: not reported

(4) Length of hospital stay (median):

(A) 2.2 days less than group $B$

(B) Not reported

(5) Cost-effectiveness:

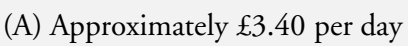

(B) Not reported

(6) Adverse events: not reported

Trial did report that 1 patient in each group was left to heal by granulation but the time to healing was not reported 
Goode 1979 (Continued)

Risk of bias

\begin{tabular}{|c|c|c|}
\hline Bias & Authors' judgement & Support for judgement \\
\hline $\begin{array}{l}\text { Random sequence generation (selection } \\
\text { bias) }\end{array}$ & Unclear risk & $\begin{array}{l}\text { "...each patient was allocated to treatment } \\
\text { with either Debrisan or Eusol by means of } \\
\text { cards drawn from a sealed envelope" (p325) } \\
\text {. However, the method used for generating } \\
\text { the randomisation sequence for the cards } \\
\text { was not reported. Hence, it was judged to } \\
\text { be unclear }\end{array}$ \\
\hline Allocation concealment (selection bias) & Unclear risk & $\begin{array}{l}\text { Although "sealed envelopes" are docu- } \\
\text { mented no further details are given }\end{array}$ \\
\hline $\begin{array}{l}\text { Blinding (performance bias and detection } \\
\text { bias) } \\
\text { Participants and personnel }\end{array}$ & Unclear risk & $\begin{array}{l}\text { Participants - blinding not stated but lack } \\
\text { of blinding unlikely to influence results } \\
\text { Personnel - blinding not stated but unlikely } \\
\text { to be achievable due to different properties } \\
\text { (beads versus ribbon gauze). Lack of blind- } \\
\text { ing unlikely to influence results }\end{array}$ \\
\hline $\begin{array}{l}\text { Blinding (performance bias and detection } \\
\text { bias) } \\
\text { Outcome assessors }\end{array}$ & Low risk & $\begin{array}{l}\text { Outcome assessor - blinded to treatment } \\
\text { "an independent assessor decided when the } \\
\text { wound was clean" using photographs of the } \\
\text { wound (p325) }\end{array}$ \\
\hline $\begin{array}{l}\text { Incomplete outcome data (attrition bias) } \\
\text { All outcomes }\end{array}$ & Low risk & $\begin{array}{l}20 \text { patients studied, } 20 \text { patients "mean time } \\
\text { to secondary wound closure reported" re- } \\
\text { ported within table } 1(\mathrm{p} 325) \text {. One patient } \\
\text { in each treatment group did not achieve } \\
\text { wound secondary wound closure }\end{array}$ \\
\hline Selective reporting (reporting bias) & Low risk & $\begin{array}{l}\text { No study protocol available but expected } \\
\text { outcomes reported } \\
\text { "Efficacy of treatment assessed by time } \\
\text { taken to allow secondary skin closure, by } \\
\text { the condition of the wound after closure } \\
\text { and the number of days in hospital" (p328) } \\
\text { all reported on although limited details } \\
\text { given for the later } 2\end{array}$ \\
\hline
\end{tabular}

Debridement for surgical wounds (Review) 
Methods

Participants
RCT

Setting: hospital, Belgium

$\mathrm{n}=40$

(A) 20 (10 men, 10 women)

(B) 20 (10 men, 10 women)

Age: 3 to 89 years

Infected post surgical wounds, oozing, covered in pus and debris

Patients all gave informed consent

Inclusion criteria: patients hospitalised in the surgical unit presenting with infected postoperative wounds, covered in pus and debris

Surgery: ranged from osteosynthesis, microsurgery, reconstructive procedures; surgical site not reported

Exclusion criteria: patients with diabetes, vascular insufficiency, severe anaemia and serum albumin less than $30 \mathrm{~g} / \mathrm{L}$
Duration of the trial was 12 days

(A) Dressing changed daily: wound cleansed - no details of the technique given; a salinesoaked compress was applied and this was covered by a $3 \mathrm{~mm}$ layer of dextranomer paste, covered with a compress and bandaged

(B) Dressing changed daily; wound cleansed; then a gauze dressing soaked in $10 \%$ aqueous polyvinylpyrrolidone was applied, covered with a dry dressing and bandaged Further changes of the dressings for groups A and B were dictated by the degree of soakage of the dressings
Outcomes
Primary outcomes:

(1) Time to a clean wound bed - changes evaluated using specific variables; degree of erythema; degree of pus and debris; oedema; necrosis; granulation tissue. The results for each variable were assessed subjectively and presented individually

Degree of erythema (reported using a 0 to 3 degree table): no significant difference reported ( 2 wounds in group A and 2 in group B did not have any erythema and were excluded from the evaluation of this variable)

Oedema (reported using a 0 to 3 degree table): no significant difference ( 2 wounds in group $A$ and 2 in group $B$ did not have any oedema and were excluded from the evaluation)

Necrosis (reported as a percentage of the total area of the wound): no significant difference ( 4 wounds in group A and 10 in group B did not exhibit any necrotic material and were excluded from the evaluation)

Pus and debris (reported as a percentage of the total area of the wound): (1 wound in group B did not have any pus or debris and was excluded from the evaluation)

No significant difference between the days of treatment or cleaning of the wounds. However, the trial also reported a further division of group A and B for evaluation of this variable, but it was unclear as to when this division was made and the handling and reporting of the data was unclear, subjective and the groups were not comparable at baseline. So while the subgroup of group A showed a higher degree of improvement in the removal of pus and debris and this was reported as significant $(P<0.05$, Student's ttest) the poor handling and subjective nature of the data makes this outcome unreliable. The subgroup of group B did not demonstrate a significant difference Granulation tissue: 
Michiels 1990 (Continued)

Mean time to a clean wound bed (SD not reported):

(A) mean 6.5 days

(B) mean 5.2 days

No significant difference (1 wound in group A and 2 in Group B did not have any granulation tissue by the end of the trial and were excluded from the evaluation)

(2) Time to complete healing: not reported Secondary outcomes:

(1) Patient satisfaction: not reported

(2) Rate of infection: not reported

(3) Quality of life: not reported

(4) Length of hospital stay: not reported

(5) Cost-effectiveness: not reported

(6) Adverse events: 1 patient in group B had an allergic reaction with oedema and erythema after 10 days and the treatment was discontinued

Notes

The development and testing of the comparison tables was not reported, therefore it is not possible to determine the reliability and validity of these tables. While the mean days for granulation tissue was reported, no other data or statistics were presented

\section{Risk of bias}

\begin{tabular}{l|l|l}
\hline Bias & Authors' judgement & Support for judgement \\
\hline $\begin{array}{l}\text { Random sequence generation (selection } \\
\text { bias) }\end{array}$ & Low risk & $\begin{array}{l}\text { "The patients were allotted to one or other of } \\
\text { the preparations according to a randomisation list" } \\
\text { (p284) }\end{array}$ \\
\hline Allocation concealment (selection bias) & Unclear risk & No details given about allocation concealment \\
\hline $\begin{array}{l}\text { Blinding (performance bias and detection } \\
\text { bias) } \\
\text { Participants and personnel }\end{array}$ & Unclear risk & $\begin{array}{l}\text { Participants - blinding not stated but blinding un- } \\
\text { likely to influence outcome } \\
\text { Personnel - blinding not stated but unlikely to be } \\
\text { achievable due to different properties (application of } \\
\text { paste versus soaked dressings). Lack of blinding un- } \\
\text { likely to influence results }\end{array}$
\end{tabular}

Blinding (performance bias and detection Unclear risk bias)

Outcome assessors

Incomplete outcome data (attrition bias) Unclear risk All outcomes
Outcome assessor - blinding not stated, p284 states that the "status of the wound was recorded each day by the same doctor when the dressing was changed" but no further detail is given

Of the 5 criteria to be reported on (granulation, pus and debris, erythema, oedema and necrosis) data are included within report on all 5 with missing data accounted for (for example within 'necrosis' 4 patients in one arm had no necrosis at the start or during so not reported)

One patient in the control group exhibited an allergic reaction to treatment therefore treatment was dis- 
Michiels 1990 (Continued)

continued (p288); it is not clear how this withdrawal was dealt with in the data presented

Selective reporting (reporting bias) Low risk

No study protocol available but expected outcomes reported

States that "aim of study was to assess and compare the clinical effects of dextranomer paste and a control treatment with polyvinylpyrrolidone (PVP) in a trial of patients with infected post-operative wounds. All variables dealing with cleansing, inflammation reducing effect, and different signs of ongoing healing were studied" (p284). Reporting of granulation, pus and debris, erythema, oedema and necrosis is given within the report

Poulson 1983

Methods

Participants
RCT

Setting: hospital, Denmark

(A) 7

(B) 11

5 men/13 women

Age: 26 to 86 years

Patients with infected laparotomy wounds, a minimum of $7 \mathrm{~cm}$, requiring opening and drainage

Inclusion criteria: wound infection following laparotomy surgery; operations included: appendicectomy, bowel surgery, cholecystectomy, hysterectomy, repair of ventral hernia, wound infection which necessitated opening and drainage of the wound

Minimum length of wound $7 \mathrm{~cm}$

Maximum depth of wound $7 \mathrm{~cm}$

Exclusion criteria: patients with burst abdomen, stoma or fistula in the vicinity of the wounds, because this increased the risk of continuous wound contamination

Interventions

A and B: initial drainage and removal of necrotic tissue method of removal not stated All wounds dressed with saline dressings to secure haemostasis

(A) Twice-daily dressings, necrotic tissue removed; dressing soaked in $20 \mathrm{ml}$ solution (streptokinase/streptodornase) applied; solution provided by hospital pharmacy

(B) Twice-daily dressings, necrotic tissue removed; dressing soaked in $20 \mathrm{ml}$ solution applied; solution provided by hospital pharmacy (saline)

Outcomes

Primary outcome: mean time to clean wound bed and closure by secondary suture:

(A) 5.00 days $(\mathrm{SD}=2.16)$

(B) 13.45 days $(\mathrm{SD}=6.77)$

Statistically significant $(\mathrm{P}<0.05$, both Student's t-test and Mann-Whitney U-test $)$

Secondary outcomes:

(1) Patient satisfaction: neither group of patients complained of significant wound dis-

Debridement for surgical wounds (Review)

Copyright () 2013 The Cochrane Collaboration. Published by John Wiley \& Sons, Ltd. 
Poulson 1983 (Continued)

comfort; no data or statistics presented

(2) Rate of infection: not reported

(3) Quality of life: not reported

(4) Length of hospital stay (median):

(A) 2.2 days less than group $B$

(B) Not reported

(5) Cost-effectiveness: not reported

(6) Adverse events: 3 patients were excluded from the evaluation for non completion of the treatment; in group A 1 patient died of a pulmonary embolism and the other required further surgery for intra-abdominal sepsis; 1 patient in group B was withdrawn as a result of abdominal dehiscence

Notes

Risk of bias

\begin{tabular}{|c|c|c|}
\hline Bias & Authors' judgement & Support for judgement \\
\hline $\begin{array}{l}\text { Random sequence generation (selection } \\
\text { bias) }\end{array}$ & Unclear risk & $\begin{array}{l}\text { "Pharmacy undertook the randomization" (p245) } \\
\text {, however no details are given regarding how this } \\
\text { randomisation was done }\end{array}$ \\
\hline Allocation concealment (selection bias) & Low risk & $\begin{array}{l}\text { Pharmacy prepared the solutions ( } 20 \mathrm{ml} \text { Varidase or } \\
20 \mathrm{ml} \text { saline) }\end{array}$ \\
\hline
\end{tabular}

Blinding (performance bias and detection Unclear risk bias)

Participants and personnel

Blinding (performance bias and detection Unclear risk bias)

Outcome assessors

Incomplete outcome data (attrition bias) High risk All outcomes
Not explicitly stated and therefore judged as unclear. However, it would be highly unlikely that participants and personnel would have been able to tell which solution was being applied as both ampoules contained $20 \mathrm{ml}$ of clear solution, so unlikely to influence results. On p246 the authors state "only when the code was broken 11 patients were found to have saline and 7 had Varidase"

Not explicitly stated and therefore judged as unclear. However, it would be highly unlikely that outcome assessors would have been able to tell which solution was being applied as both ampoules contained 20 $\mathrm{ml}$ of clear solution, so unlikely to influence results. On p246 the authors state "only when the code was broken 11 patients were found to have saline and 7 had Varidase"

From the 21 originally recruited, 3 were withdrawn: 2 from the placebo group and one from the Varidase group. These 3 were excluded from the results presented and therefore no ITT analysis was undertaken. Rationales were given for the withdrawal 
Poulson 1983 (Continued)

\begin{tabular}{|l|l|l} 
Selective reporting (reporting bias) & $\begin{array}{l}\text { No study protocol available } \\
\text { The stated aim of the trial was "to show, by means of } \\
\text { a prospective clinical trial with randomised double } \\
\text { blind procedure if Varidase is superior to conven- } \\
\text { tional management of infected laparotomy wounds" } \\
\text { (p245). However, they do not state what constitutes } \\
\text { superior' and how this would be measured. The } \\
\text { study reports number of days required for wound } \\
\text { dressing and number of days in hospital (within dis- } \\
\text { cussion section). Size of wound and type of bacterial } \\
\text { growth recorded at the start of the trial; this is not } \\
\text { reported on again within the results }\end{array}$ \\
\hline
\end{tabular}

Sondergaard 1982

$\begin{array}{ll}\text { Methods } & \text { RCT }\end{array}$

Setting: hospital inpatient and outpatient, Denmark

Participants

$\mathrm{n}=28$ started the trial and 22 completed the trial

(A) 10

(B) 12

Numbers of men and women not reported

Participants ages not reported

Consent was not reported but patients were provided with oral and written objectives of the study

Study was in accordance with the Helsinki declaration, 1975

Inclusion criteria: patients with suppurating infected surgical wounds involving subcutaneous tissue

Exclusion criteria: patients prescribed systemic steroid therapy; patients receiving another local wound intervention; patients with substantial wound revision and if there was peritoneal communication

Interventions

A microbiological swab was taken from the bottom of each wound at the start of the trial and on every 7 th day until the wound was clean; this was to document the bacterial flora to register any favourable influences of the dressings

(A) Wound irrigated with saline; dextranomer beads made into a paste and applied to the wound; covered with a sterile compress; dressing changed at least daily and before it became fully saturated

(B) Dressing soaked in $0.1 \%$ chloramine solution; covered with a sterile compress; changed once daily and 2 or 3 times if saturated; dressings changed by senior registrars; trial authors undertook assessment of the wounds

Outcomes

Primary outcomes:

(1) Time to clean wound bed (reported as the median: mean, SD or SEM not reported for any of the results):

(A) 6 days

(B) 5 days

(2) Time until the wound was clinically assessed as ready for outpatient treatment (me-

Debridement for surgical wounds (Review) 


dian):
(A) 9 days
(B) 7 days
(3) Time to wound healing (median):
(A) 27 days
(B) 20 days
Observed results were compared and assessed using the Mann-Whitney U-test; no sig-
nificant difference reported; detailed data and statistics not included
Secondary outcomes:
(1) Patient satisfaction: dressing changes were less painful in group A; no data or statistics
presented
(2) Rate of infection: not reported; results of microbiological wound swabs not reported
(3) Quality of life: not reported
(4) Length of hospital stay: not reported
(5) Cost-effectiveness:
(A) Approximately 123 Danish Kroner per dressing change
(B) Approximately 1.50 Danish Kroner per dressing change
Cost analysis not presented
(6) Adverse events: 4 patients excluded from group A: 2 patients died, cause of death
not reported; 1 had peritoneal communication; in 1 the wound was too undermined for
application of the paste; 2 excluded from group B: 1 had heavy growth of bacteria and
the dressing was changed to acetic alumina; 1 had a total wound rupture

Notes

The trial authors did observe more granulation tissue; less irritation and less pain on dressing changes with the dextranomer dressing. Blinding of assessors (trial authors) is not reported. The original paper was in German and the data were extracted after being translated into English 
Sondergaard 1982 (Continued)

(senior registrars) were blinded or not

Blinding (performance bias and detection Unclear risk bias)

Outcome assessors

Incomplete outcome data (attrition bias) High risk

All outcomes
It is unclear from the trial if the assessors (the study authors) were blinded

A total of 6 patients were excluded from the study ( 2 from the chloramine and 4 from the Debrisan), a rationale for the exclusions is given and exclusions are mentioned in the presented in results tables. It is not clear if these were also excluded from the final analysis. Also, the dropout rate was $21 \%$ (> $10 \%$ ) and hence judged to be unacceptable

Selective reporting (reporting bias) Unclear risk

No study protocol is available. No study aims or outcomes are stated in the paper. Results reported include: number of days from start of treatment to a clean wound; number of days until wound assessed as ready for outpatient treatment; number of days until wound healed. It is apparent that the intention was also to examine the number of daily wound dressing changes required but this was abandoned due to insufficient recording (p1524)

Young 1982

\begin{tabular}{ll}
\hline Methods & RCT \\
& Setting: hospital and outpatient clinic, UK \\
\hline Participants & $\mathrm{n}=50$ \\
(A) 25 & (B) 25 \\
Numbers of men and women not reported \\
Mean age (years): \\
(A) 44.48, SD 5.17 \\
(B) 49.64, SD 4.57 \\
Patients with surgical wound breakdown \\
Consent not reported \\
Inclusion criteria: patients undergoing surgery for perforated or gangrenous appendix, \\
where the wound was left open from the muscle layer outwards; patients with surgical \\
wound breakdown postoperatively \\
No exclusion criteria listed \\
\hline
\end{tabular}

Interventions

Each wound was measured at the start of the trial:

Mean length $(\mathrm{cm})$ :

(A) $5.53, \mathrm{SD} 0.55$

Debridement for surgical wounds (Review)

Copyright @ 2013 The Cochrane Collaboration. Published by John Wiley \& Sons, Ltd. 
(B) 6.57, SD 0.89

Mean breadth $(\mathrm{cm})$ :

(A) 2.25 , SD 0.33

(B) 2.48, SD 0.32

Mean depth $(\mathrm{cm})$ :

(A) 1.80, SD 0.20

(B) $2.24, \mathrm{SD} 0.29$

Mean volume ( $\mathrm{ml})$ :

(A) 4.92, SD 1.15

(B) 6.37, SD 1.30

Individual wounds were photographed

All wounds were initially treated with gauze packing for the first 48 hours

(A) Dextranomer beads applied twice-daily: reduced to once a day when the discharge reduced

(B) Silastic foam dressing applied, and this was removed and cleaned twice a day; reduced to once a day with reduction in the discharge

All wounds were reviewed on 1st, 3rd and 7th days and then weekly. Patients discharged home had their wounds reviewed weekly

The review included: photograph, measurement of the wound, review of erythema, oedema, rash, odour and slough

Comfort of the dressing was assessed by questioning the patient

Pain was graded using an ordinal scale $(0=$ no pain to $3=$ severe pain $)$

(1) Time to disappearance of erythema, oedema and slough: similar in group A and group B; data and statistics not reported

(2) Mean time to complete healing (days):

(A) 40.92, SD 3.98

(B) $36.96, \mathrm{SD} 3.18$

Results subjected to analysis using the Student's t-test

Secondary outcomes:

(1) Patient satisfaction: mean days until pain free dressings

(A) 5.32 , SD 0.55 days

(B) 5.64, SD 0.45 days

Results subjected to analysis using the Student's t-test

Wound pain reported as similar for both groups

(2) Rate of infection: not reported

(3) Quality of life: not reported

(4) Length of hospital stay: not reported

(4) Cost-effectiveness: authors quoted the costs as calculated in a previous study (Goode 1979):

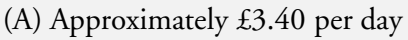

(B) Approximately $£ 0.75$ per week; no data or statistical evidence reported

(6) Adverse events: not reported

An ordinal scale is used to assess the pain at dressing changes. This may result in skewed data, so a non parametric Mann-Whitney U-test may have been more appropriate than the Student's t-test. Also there was a methodological flaw in the analysis of the data and time to complete healing and time to a pain-free wound, which should have been 
expressed as a hazard ratio and not as continuous data

\section{Risk of bias}

\begin{tabular}{|c|c|c|}
\hline Bias & Authors' judgement & Support for judgement \\
\hline $\begin{array}{l}\text { Random sequence generation (selection } \\
\text { bias) }\end{array}$ & Unclear risk & $\begin{array}{l}\text { "Patients were allocated to receive either } \\
\text { Debrisan or Silastic foam elastomer by } \\
\text { means of a random card system" (p33). Not } \\
\text { clear if the cards were randomised. How- } \\
\text { ever, the method used for generating the } \\
\text { randomisation sequence for the cards was } \\
\text { not reported. Hence, it was judged to be } \\
\text { unclear }\end{array}$ \\
\hline Allocation concealment (selection bias) & Unclear risk & Allocation concealment not stated \\
\hline $\begin{array}{l}\text { Blinding (performance bias and detection } \\
\text { bias) } \\
\text { Participants and personnel }\end{array}$ & Unclear risk & $\begin{array}{l}\text { It is not reported if participants were } \\
\text { blinded to treatment, however blinding } \\
\text { would be unlikely to affect results. Blinding } \\
\text { or not of personnel to treatment is not re- } \\
\text { ported, however due to the different prop- } \\
\text { erties of the dressings this would be un- } \\
\text { achievable }\end{array}$ \\
\hline $\begin{array}{l}\text { Blinding (performance bias and detection } \\
\text { bias) } \\
\text { Outcome assessors }\end{array}$ & Unclear risk & $\begin{array}{l}\text { Limited information given within the pa- } \\
\text { per: "wounds were reviewed" (p33) but it } \\
\text { is not stated by whom and if they were } \\
\text { blinded to the intervention }\end{array}$ \\
\hline $\begin{array}{l}\text { Incomplete outcome data (attrition bias) } \\
\text { All outcomes }\end{array}$ & Low risk & $\begin{array}{l}\text { No loss to follow up reported, } 50 \text { patients } \\
\text { completed the trial ( } 25 \text { in each arm) }\end{array}$ \\
\hline Selective reporting (reporting bias) & Low risk & $\begin{array}{l}\text { No study protocol is available but appro- } \\
\text { priate study outcomes reported } \\
\text { The aim of the trial was to "compare the } \\
\text { efficacy of these two dressings in surgical } \\
\text { wounds that have either broken down or } \\
\text { have been left open postoperatively" (p33) } \\
\text { It is not stated how "efficacy" will be mea- } \\
\text { sured at the outset. Time to heal and time } \\
\text { to pain-free are reported within the trial; } \\
\text { presence of erythema, odour, slough and } \\
\text { rash were also reported }\end{array}$ \\
\hline
\end{tabular}

$A=$ intervention group

$\mathrm{B}=$ control group

ITT $=$ intention-to-treat

Debridement for surgical wounds (Review) 
RCT $=$ randomised controlled trial

$\mathrm{SD}=$ standard deviation

$\mathrm{SEM}=$ standard error of the mean

Characteristics of excluded studies [ordered by study ID]

\begin{tabular}{|c|c|}
\hline Study & Reason for exclusion \\
\hline Allie 2004 & Non-randomised retrospective method \\
\hline Bethell 2003 & Literature review, not a research study \\
\hline Cannavo 1998 & RCT: comparison of alginate with gauze dressings for healing of surgical wounds, not of debridement \\
\hline Capasso 2003 & Non-experimental retrospective chart review \\
\hline Cohn 2004 & Comparison of hydrofibre to wet to dry dressings for healing rates of surgical wounds, not of debridement \\
\hline De Feo 2001 & Retrospective chart review of wound infections over 20 years \\
\hline De Feo 2003 & Retrospective non-randomised study \\
\hline Doughty 2005 & Management of surgical wound dehiscence and not a research paper \\
\hline Douville 2004 & Retrospective review of managing sternal wound complications \\
\hline Edwards 1967 & Clean surgical wound healing by primary intention - no debridement required \\
\hline Foster 2000 & Abscess wounds \\
\hline Gliantsev 1996 & In vitro study \\
\hline Gottrup 2005 & A review, not RCT \\
\hline Granick 2006 & $\begin{array}{l}\text { Retrospective study of patients records: debridement of a range of wounds, including pressure ulcers, trauma } \\
\text { wounds and surgical wound complications }\end{array}$ \\
\hline Guest 2005 & Not RCT: models used to estimate the cost of 2 dressings \\
\hline Kuleshov 1992 & Not RCT: chronic wounds \\
\hline Moore 2000 & Included abscesses; did not measure debridement \\
\hline Moore 2001 & Systematic review \\
\hline Moues 2004 & Wounds treated prior to surgical closure \\
\hline
\end{tabular}

Debridement for surgical wounds (Review) 
(Continued)

Mulder 1995 Non-randomised study; debridement of chronic wounds

Rand 1998 Compared methods of wound closure for dehiscence, rather than debridement methods

Soul 1978 Not RCT: study included a range of wounds including pressure ulcers

Tolstykh 1987 Not RCT: no randomisation method identified

Williams 1995 Abscess wounds

Zeitani $2004 \quad$ Not RCT: controlled study

$\mathrm{RCT}=$ randomised controlled trial 


\section{DATA ANDANALYSES}

This review has no analyses.

\section{WHAT'S NEW}

Last assessed as up-to-date: 13 June 2013.

\begin{tabular}{lll}
\hline Date & Event & Description \\
\hline 13 June 2013 & New citation required but conclusions have not changed & $\begin{array}{l}\text { No new studies identified for inclusion. The conclusions } \\
\text { remain the same }\end{array}$ \\
\hline 13 June 2013 & New search has been performed & Third update, new search. \\
\hline
\end{tabular}

\section{H I S T O R Y}

Protocol first published: Issue 4, 2006

Review first published: Issue 3, 2008

\begin{tabular}{lll}
\hline Date & Event & Description \\
\hline 13 April 2011 & $\begin{array}{l}\text { New citation required but conclusions have not } \\
\text { changed }\end{array}$ & New lead author and contact person \\
\hline 13 April 2011 & New search has been performed & $\begin{array}{l}\text { Second update, new search, no new studies included. } \\
\text { Risk of bias assessment completed on all included stud- } \\
\text { ies. The conclusions remain unchanged }\end{array}$ \\
\hline 12 January 2011 & New search has been performed & $\begin{array}{l}\text { First update, new searches, no new studies identified, } \\
\text { conclusions remain unchanged }\end{array}$ \\
\hline 17 February 2010 & Amended & Contact details updated. \\
\hline 24 April 2008 & Amended & Converted to new review format. \\
\hline
\end{tabular}




\section{CONTRIBUTIONSOFAUTHORS}

ND and MM researched and developed the background information.

ND, JD, MM and FS contributed to the formulation of the objective and criteria for considering studies for the review.

ND prepared the search strategy for the review.

JD and FS completed the methods of the review.

ND and FS independently assessed the titles and abstracts of studies identified for relevance and design. The authors obtained full versions of articles that met the inclusion criteria of this initial assessment. MM was consulted for adjudication on some abstracts and she reviewed all rejected titles and abstracts.

Data extraction using a standard extraction sheet was performed by ND and JD independently. Any discrepancies were resolved by discussion and referred to FS.

Quality of studies was assessed independently by ND and MM.

ND and JD extracted the data from the studies, ND undertook initial analysis and interpreted the data. The review was drafted by ND and FS with some editing by MM. Responses and amendments following peer review were undertaken by ND and FS.

FS and JD independently reviewed the titles and abstracts following the updated searches.

FS completed the risk of bias assessment for included trials and updated the review.

\section{Contributions of editorial base:}

Nicky Cullum: edited the review, advised on methodology, interpretation and review content. Approved the final review and review updates prior to submission.

Sally Bell-Syer: coordinated the editorial process. Advised on methodology, interpretation and content. Edited and the review and the updated reviews.

Ruth Foxlee: designed the search strategy, ran the searches and edited the search methods section for the updates.

\section{DECLARATIONSOF INTEREST}

None known.

\section{SOURCES OF SUPPORT}

\section{Internal sources}

- School of Nursing, Midwifery and Social Care, UK. 


\section{External sources}

- NIHR/Department of Health (England), (Cochrane Wounds Group), UK.

- Grant worth $£ 15,000$, from the Centre for Integrated Healthcare Research, UK.

\section{NDEX TERMS}

\section{Medical Subject Headings (MeSH)}

Bandages; Debridement [ ${ }^{*}$ methods]; Dextrans [therapeutic use]; Randomized Controlled Trials as Topic; Sodium Chloride [administration $\&$ dosage]; Streptodornase and Streptokinase [therapeutic use]; Surgical Wound Infection [* ${ }^{*}$ surgery]; Wound Healing

\section{MeSH check words}

Humans 